\title{
Prevalence and clinical impact of vitamin D deficiency in critically ill Korean patients with traumatic injuries: a single-center, prospective, observational study
}

\author{
Kyoung Hoon Lim, Jihoon Jang, Jinyoung Park \\ Trauma Center, Department of Surgery, Kyungpook National University Hospital, School of Medicine, Kyungpook National University, Daegu, Korea
}

Background: This study investigated the prevalence and impact of 25-hydroxyvitamin D $(25(\mathrm{OH})$ vitamin D) deficiency in critically ill Korean patients with traumatic injuries.

Methods: This prospective observational cohort study assessed the $25(\mathrm{OH})$ vitamin D status of consecutive trauma patients admitted to the trauma intensive care unit (TICU) of Kyungpook National University Hospital between January and December 2018. We analyzed the prevalence of $25(\mathrm{OH})$ vitamin D deficiency and its impact on clinical outcomes.

Results: There were no significant differences in the duration of mechanical ventilation (MV), lengths of TICU and hospital stays, and rates of nosocomial infection and mortality between patients with $25(\mathrm{OH})$ vitamin $\mathrm{D}<20 \mathrm{ng} / \mathrm{ml}$ and those with $25(\mathrm{OH})$ vitamin $\mathrm{D} \geq 20 \mathrm{ng} / \mathrm{ml}$ within 24 hours of TICU admission. The duration of MV and lengths of TICU and hospital stays were shorter and the rate of nosocomial infection was lower in patients with $25(\mathrm{OH})$ vitamin D level $\geq 20 \mathrm{ng} / \mathrm{ml}$ on day 7 of hospitalization. The duration of MV, lengths of TICU and hospital stays, and nosocomial infection rate were significantly lower in patients with increased concentrations compared with those with decreased concentrations on day 7 of hospitalization, but the mortality rate did not differ significantly.

Conclusions: The $25(\mathrm{OH})$ vitamin D level measured within 24 hours after TICU admission was unrelated to clinical outcomes in critically ill patients with traumatic injuries. However, patients with increased $25(\mathrm{OH})$ vitamin D level after 7 days of hospitalization had better clinical outcomes than those with decreased levels.

Key Words: Deficiency; Trauma; Vitamin D

\section{Original Article}

Received: September 29, 2020

Revised: February 23, 2021

Accepted: February 24, 2021

Corresponding author Jinyoung Park

Department of Surgery, Kyungpook National University Hospital, 130 Dongdeok-ro, Jung-gu, Daegu 41944, Korea

Tel: +82-53-420-5605

Fax: +82-53-421-0510

E-mail: kpnugs@knu.ac.kr

\section{INTRODUCTION}

Vitamin D is an important pro-hormone that is produced in the skin after exposure to ultraviolet (UV) B radiation or is obtained from the diet [1-4]. It is hydroxylated in the liver to 25-hydroxyvitamin $\mathrm{D}(25(\mathrm{OH})$ vitamin $\mathrm{D})$ and further hydroxylated in the kidney to 1,25-dihydroxyvitamin $\mathrm{D}\left(1,25(\mathrm{OH})_{2}\right.$ vitamin $\left.\mathrm{D}\right)$, the active hormone involved in serum calcium and phosphorus homeostasis for optimal neuromuscular function. Vitamin D plays an important role in the innate and acquired immune systems, especially in patients with infectious disease, diabetes mellitus, myocardial infarction, cardiac failure, stroke, Alzheimer disease, os-

Copyright @ 2021 The Korean Society of Critical Care Medicine

This is an Open Access article distributed under the terms of Creative Attributions Non-Commercial License (https:// creativecommons.org/li-censes/by-nc/4.0/ which permits unrestricted noncommercial use, distribution, and reproduction in any medium, provided the original work is properly cited. 
teoporosis, inflammatory bowel disease, chronic obstructive airway disease, and autoimmune disease [5-7]. In particular, vitamin D deficiency is identified frequently in patients in the intensive care unit (ICU); patients in the ICU have lower vitamin D level than the general population. Vitamin D level in critically ill patients can affect their clinical outcomes, such as the duration of mechanical ventilation (MV) and rates of complications, morbidity, and mortality [5-10]. Trauma patients often are hospitalized for sudden accidents that occur during daily activities. Therefore, deficiency of vitamin D, which is synthesized by exposure to UV light, is less prevalent in these patients than in those hospitalized with diseases. In addition, trauma leads to a very serious stress response, including inactivation of the immune system, leaving trauma patients vulnerable to infections such as bacteremia, urinary tract infection, pneumonia, and wound infections, as well as complications during hospitalization. To date, only a few studies have assessed the effects of blood vitamin D level on clinical outcomes in trauma patients. Therefore, the present study investigated the prevalence of vitamin D deficiency in patients with severe trauma and the relationship between serum $25(\mathrm{OH})$ vitamin D level and clinical outcomes of duration of MV, lengths of trauma ICU (TICU) and hospital stays, and rates of nosocomial infection and mortality.

\section{MATERIALS AND METHODS}

This prospective observational cohort study included all trauma patients aged $\geq 18$ years who were consecutively admitted to the TICU at the trauma center of Kyungpook National University Hospital within 24 hours of trauma injury between January and December 2018. The study protocol was in accordance with the Declaration of Helsinki and approved by the Institutional Review Board of Kyungpook National University Hospital (IRB No. 2016-11-025-002). Written informed consent was obtained from all patients or their family members. Patients who did not stay in the TICU for $\geq 24$ hours or who were administered multivitamin supplements or medications that could affect $25(\mathrm{OH})$ vitamin D level within 7 days of administration were excluded. The following patient information was collected from the electronic medical record system of the hospital: age, sex, body mass index (BMI), trauma mechanism, nutrition status (enteral or parenteral nutrition for $\geq 3$ days before the test on day 7), presence of shock (systolic blood pressure $<90 \mathrm{~mm} \mathrm{Hg}$ or heart rate $>120 / \mathrm{min}$ ) on admission, operation within 7 days, and measures of severity such as the Glasgow coma scale (GCS) score, injury severity score (ISS),

\section{KEY MESSAGES}

- The majority of patients with traumatic injuries were either 25-hydroxyvitamin $\mathrm{D}(25(\mathrm{OH})$ vitamin $\mathrm{D})$ deficient or insufficient.

- The $25(\mathrm{OH})$ vitamin D level measured within 24 hours after trauma intensive care unit admission was unrelated to clinical outcomes in critically ill patients with traumatic injuries.

- Patients with increased 25(OH) vitamin D level after 7 days of hospitalization had better clinical outcomes than those with decreased $\mathrm{D}$ level.

Acute Physiology and Chronic Health Evaluation (APACHE) II score, Sequential Organ Failure Assessment (SOFA) score, and Simplified Acute Physiology Score III (SAPS III). Clinical outcomes were the duration of MV, lengths of TICU and hospital stays, and rates of nosocomial infection and mortality. Blood 25(OH) vitamin D level was measured within 24 hours and after 7 days of TICU admission using the reference standard of liquid chromatography and tandem mass spectrometry (Quest Diagnostics Lab, Valencia, CA, USA). Based on a previously published study on vitamin D level in critically ill patients [9], the patients were classified into two groups according to blood $25(\mathrm{OH})$ vitamin D level measured within 24 hours of TICU admission: group A ( $<20 \mathrm{ng} / \mathrm{ml}[50 \mathrm{nmol} / \mathrm{L}])$ and group B ( $\geq 20 \mathrm{ng} / \mathrm{ml}[50 \mathrm{nmol} / \mathrm{L}])$. Continuous variables were reported as mean \pm standard deviation and compared using Student t-test, whereas categorical variables were reported as proportions (percentages) and were compared using Pearson's chi-square test or Fisher's exact test, as appropriate. The association between parameters recorded in our database was tested using binary logistic regression analysis. Factors associated with the outcome were used to build multivariate forward stepwise logistic regression models and determine independent factors related to vitamin $\mathrm{D}$ level and nosocomial infection rate. All statistical analyses were performed using SPSS ver. 17.0 (SPSS Inc., Chicago, IL, USA), with $\mathrm{P}$-values less than 0.05 considered statistically significant.

\section{RESULTS}

\section{Patient Demographics}

This study included 191 consecutive patients admitted to the TICU who met our inclusion criteria. Of these patients, 145 (75.9\%) were men, and 46 (24.1\%) were women; the mean age was $53.1 \pm 20.6$ years. Most patients (182/191, 95.3\%) were 
hospitalized after blunt trauma injury. These patients had a mean GCS score of $12.3 \pm 4.0$ (range, $3-15$ ), an ISS of $17.4 \pm 9.0$ (range, 1-75), APACHE II score of 10.7 \pm 7.3 , SOFA score of $3.3 \pm 3.1$, and SAPS III of $45.2 \pm 15.7$.

Table 1. Serum 25(OH) vitamin D levels measured within 24 hours of TICU admission

\begin{tabular}{lcc}
\hline Group & No $(\%)$ & Mean \pm SD $(\mathrm{ng} / \mathrm{ml})$ \\
\hline Deficient $(<10 \mathrm{ng} / \mathrm{ml})$ & $109(57.1)$ & $6.1 \pm 0.2$ \\
Insufficient $(10-29 \mathrm{ng} / \mathrm{ml})$ & $78(40.8)$ & $15.4 \pm 0.2$ \\
Sufficient $(30-100 \mathrm{ng} / \mathrm{ml})$ & $4(2.1)$ & $36.8 \pm 3.9$ \\
Total & $191(100)$ & $10.6 \pm 7.0$ \\
\hline
\end{tabular}

25(OH) vitamin D: 25-hydroxyvitamin D; TICU: trauma intensive care unit; SD: standard deviation.

Table 2. Demographic characteristics and clinical outcomes in TICU patients with $25(\mathrm{OH})$ vitamin D levels $<20 \mathrm{ng} / \mathrm{ml}$ and $\geq 20$ $\mathrm{ng} / \mathrm{ml}$ measured within 24 hours of TICU admission

\begin{tabular}{|c|c|c|c|}
\hline Variable & $\begin{array}{c}\text { Vitamin D } \\
(<20 \mathrm{ng} / \mathrm{ml}, \\
n=175)\end{array}$ & $\begin{array}{c}\text { Vitamin D } \\
(\geq 20 \mathrm{ng} / \mathrm{ml}, \\
n=16)\end{array}$ & P-value \\
\hline $25(\mathrm{OH})$ vitamin D (ng/ml) & $8.9 \pm 4.4$ & $27.7 \pm 7.0$ & 0.000 \\
\hline Age (yr) & $52.9 \pm 20.5$ & $55.1 \pm 22.3$ & 0.680 \\
\hline Male sex & $133(76)$ & $12(75)$ & 1.000 \\
\hline $\mathrm{BMI}\left(\mathrm{kg} / \mathrm{m}^{2}\right)$ & $23.2 \pm 3.8$ & $23.7 \pm 4.1$ & 0.602 \\
\hline GCS score & $12.4 \pm 3.9$ & $11.1 \pm 4.6$ & 0.195 \\
\hline Injury severity score & $17.6 \pm 9.1$ & $15.3 \pm 8.3$ & 0.336 \\
\hline Blunt injury (\%) & $166(94.9)$ & $16(100)$ & 1.000 \\
\hline Presence of shock on admission & $43(24.6)$ & $3(18.8)$ & 0.765 \\
\hline $\mathrm{CRP}(\mathrm{mg} / \mathrm{dl})$ & $0.4 \pm 1.6$ & $0.7 \pm 1.1$ & 0.482 \\
\hline APACHE II score & $10.6 \pm 7.4$ & $11.8 \pm 6.1$ & 0.529 \\
\hline SOFA score & $3.3 \pm 3.2$ & $3.4 \pm 2.8$ & 0.897 \\
\hline SAPS III score & $44.9 \pm 15.6$ & $47.3 \pm 17.2$ & 0.570 \\
\hline $\begin{array}{l}\text { RBC units transfused within } \\
24 \text { hours }\end{array}$ & $3.4 \pm 6.2$ & $0.3 \pm 0.6$ & 0.000 \\
\hline Total serum calcium (mg/dl) & $7.9 \pm 7.7$ & $8.4 \pm 0.8$ & 0.038 \\
\hline Duration of MV (day) & $3.5 \pm 7.5$ & $7.0 \pm 17.9$ & 0.449 \\
\hline Length of TICU stay (day) & $9.5 \pm 11.2$ & $11.0 \pm 19.3$ & 0.635 \\
\hline Length of hospital stay (day) & $29.3 \pm 29.9$ & $24.4 \pm 31.9$ & 0.531 \\
\hline Nosocomial infection (\%) & 78 (44.6) & $7(43.8)$ & 0.950 \\
\hline Mortality (\%) & 19 (10.9) & $2(12.5)$ & 0.690 \\
\hline
\end{tabular}

Values are presented as mean \pm standard deviation or number (\%) TICU: trauma intensive care unit; $25(\mathrm{OH})$ vitamin D: 25-hydroxyvitamin D; BMI: body mass index; GCS: Glasgow coma scale; CRP: C-reactive protein; APACHE: Acute Physiology and Chronic Health Evaluation; SOFA: Sequential Organ Failure Assessment; SAPS: Simplified Acute Physiology Score; RBC: red blood cell; MV: mechanical ventilation.

\section{Distribution and Seasonal Variation in $25(\mathrm{OH})$ Vitamin D Level at TICU Admission}

The mean serum 25(OH) vitamin D level within 24 hours of TICU admission was $10.6 \pm 7.0 \mathrm{ng} / \mathrm{ml}$. Of the 191 patients, 109 (57.1\%) had $25(\mathrm{OH})$ vitamin D deficiency $(<10 \mathrm{ng} / \mathrm{ml}), 78$ (40.8\%) had 25(OH) vitamin D insufficiency (10-29 ng/ml), and four $(2.1 \%)$ had $25(\mathrm{OH})$ vitamin D sufficiency (30-100 $\mathrm{ng} / \mathrm{ml}$ ) (Table 1). To determine whether there were seasonal variations in serum $25(\mathrm{OH})$ vitamin D level, the levels in the study patients were compared to those of 130 other patients that were admitted to the TICU from April to September and to the levels of 61 patients admitted to the TICU from October to March. The mean 25(OH) vitamin D levels in these two

Table 3. Demographic characteristics and clinical outcomes in TICU patients with $25(\mathrm{OH})$ vitamin D levels $<20 \mathrm{ng} / \mathrm{ml}$ and $\geq 20$ $\mathrm{ng} / \mathrm{ml}$ measured on day 7 of hospitalization

\begin{tabular}{lccc}
\hline Variable & $\begin{array}{c}\text { Vitamin D } \\
(<20 \mathrm{ng} / \mathrm{ml}, \\
n=142)\end{array}$ & $\begin{array}{c}\text { Vitamin D } \\
(\geq 20 \mathrm{ng} / \mathrm{ml} \text {, P-value } \\
n=11)\end{array}$ \\
\hline 25(OH) vitamin D (ng/ml) & $7.9 \pm 4.4$ & $29.1 \pm 11.7$ & 0.000 \\
Age (yr) & $51.9 \pm 20.5$ & $50.7 \pm 17.7$ & 0.846 \\
Male sex & $108(76.1)$ & $8(72.7)$ & 0.728 \\
BMI (kg/m $\left.{ }^{2}\right)$ & $22.9 \pm 3.7$ & $24.2 \pm 4.9$ & 0.285 \\
GCS score & $12.4 \pm 3.8$ & $14.7 \pm 0.7$ & 0.000 \\
Injury severity score & $17.7 \pm 8.0$ & $14.1 \pm 6.6$ & 0.152 \\
APACHE II score & $10.5 \pm 6.9$ & $6.5 \pm 4.4$ & 0.062 \\
SOFA score & $3.3 \pm 3.0$ & $1.6 \pm 1.4$ & 0.003 \\
SAPS III score & $43.5 \pm 14.6$ & $39.0 \pm 13.3$ & 0.321 \\
CRP (mg/dl) & $0.4 \pm 1.7$ & $0.9 \pm 1.5$ & 0.359 \\
RBC units transfused within & $2.7 \pm 4.4$ & $1.9 \pm 2.8$ & 0.554 \\
24 hours & & & \\
Presence of shock on admission & $38(26.8)$ & $2(18.2)$ & 0.729 \\
Nutrition ${ }^{\text {a }}$ & $98(69.0)$ & $9(81.8)$ & 0.506 \\
Operation within 7 days & $76(53.5)$ & $6(54.5)$ & 0.948 \\
Duration of MV (day) & $4.7 \pm 9.9$ & $0.1 \pm 0.3$ & 0.000 \\
Length of TICU stay (day) & $11.3 \pm 13.1$ & $5.0 \pm 4.0$ & 0.001 \\
Length of hospital stay (day) & $34.2 \pm 31.2$ & $16.2 \pm 9.5$ & 0.059 \\
Nosocomial infection (\%) & $73(51.4)$ & $1(9.1)$ & 0.007 \\
Mortality (\%) & $19(10.9)$ & $2(12.5)$ & 0.690 \\
\hline
\end{tabular}

Values are presented as mean \pm standard deviation or number (\%). TICU: trauma intensive care unit; $25(\mathrm{OH})$ vitamin D: 25-hydroxyvitamin D; BMI: body mass index; GCS: Glasgow coma scale; APACHE: Acute Physiology and Chronic Health Evaluation; SOFA: Sequential Organ Failure Assessment; SAPS: Simplified Acute Physiology Score; CRP: C-reactive protein; RBC: red blood cell; MV: mechanical ventilation.

${ }^{a}$ Cases who were received enteral or parenteral nutrition for more than 3 days before the test of 7 days. 
groups were $10.4 \pm 7.2$ and $10.9 \pm 6.6 \mathrm{ng} / \mathrm{ml}$, respectively, showing no seasonal variations $(\mathrm{P}=0.638)$.

\section{Comparison of Initial 25(OH) Vitamin D Level on Day 1}

There were no statistical differences in age, sex, BMI, GCS score, ISS, injury mechanism, presence of shock, APACHE II score, SOFA score, and SAPS III between patients with 25(OH) vitamin D level $<20 \mathrm{ng} / \mathrm{ml}$ and those with $25(\mathrm{OH})$ vitamin D level $\geq 20 \mathrm{ng} / \mathrm{ml}$. In contrast, the amount of red blood cells (RBCs) transfused within 24 hours of admission was significantly higher and the serum total calcium was significantly lower in patients with $25(\mathrm{OH})$ vitamin D level $<20 \mathrm{ng} / \mathrm{ml}$ than in those with $25(\mathrm{OH})$ vitamin D level $\geq 20 \mathrm{ng} / \mathrm{ml}$. However, there were no statistically significant differences between the groups in terms of the duration of MV, lengths of TICU and hospital stays, and rates of nosocomial infection and mortality (Table 2).

Table 4. Clinical outcomes in TICU patients showing increased and decreased $25(\mathrm{OH})$ vitamin $\mathrm{D}$ level from day 1 to day 7 of hospitalization

\begin{tabular}{|c|c|c|c|}
\hline Variable & $\begin{array}{c}\text { Decreased } \\
\text { group } \\
(n=96)\end{array}$ & $\begin{array}{c}\text { Increased } \\
\text { group } \\
(n=57)\end{array}$ & P-value \\
\hline Variance of $25(\mathrm{OH})$ vitamin D level & $-5.3 \pm 5.3$ & $6.0 \pm 7.9$ & 0.000 \\
\hline GCS score & $11.9 \pm 4.1$ & $13.6 \pm 2.9$ & 0.001 \\
\hline Injury severity score & $17.8 \pm 7.6$ & $16.7 \pm 8.6$ & 0.457 \\
\hline APACHE II score & $11.2 \pm 7.2$ & $8.5 \pm 6.1$ & 0.185 \\
\hline SOFA score & $3.5 \pm 3.2$ & $2.4 \pm 2.5$ & 0.029 \\
\hline SAPS III score & $43.8 \pm 15.4$ & $42.2 \pm 13.1$ & 0.059 \\
\hline CRP & $0.4 \pm 0.6$ & $0.3 \pm 0.8$ & 0.577 \\
\hline $\begin{array}{l}\text { RBC units transfused within } \\
24 \text { hours }\end{array}$ & $2.9 \pm 4.4$ & $2.2 \pm 4.2$ & 0.548 \\
\hline Presence of shock on admission & $31(32.3)$ & $9(15.8)$ & 0.025 \\
\hline Nutrition ${ }^{\mathrm{a}}$ & 72 (75.0) & 45 (78.9) & 0.578 \\
\hline Operation within 7 days & $50(52.1)$ & $32(56.1)$ & 0.627 \\
\hline Duration of MV (day) & $5.3 \pm 11.1$ & $2.7 \pm 6.5$ & 0.033 \\
\hline Length of TICU stay (day) & $12.7 \pm 14.6$ & $7.7 \pm 8.2$ & 0.015 \\
\hline Length of hospital stay (day) & $38.2 \pm 34.7$ & $23.9 \pm 18.8$ & 0.009 \\
\hline Nosocomial infection (\%) & $55(57.2)$ & 19 (33.3) & 0.004 \\
\hline Mortality (\%) & $7(7.3)$ & $2(3.5)$ & 0.336 \\
\hline
\end{tabular}

Values are presented as mean \pm standard deviation or number (\%).

TICU: trauma intensive care unit; $25(\mathrm{OH})$ vitamin D: 25-hydroxyvitamin D; GCS: Glasgow coma scale; APACHE: Acute Physiology and Chronic Health Evaluation; SOFA: Sequential Organ Failure Assessment; SAPS: Simplified Acute Physiology Score; CRP: C-reactive protein; RBC: red blood cell; MV: mechanical ventilation.

${ }^{a}$ Cases who were received enteral or parenteral nutrition for more than 3 days before the test of 7 days.

\section{Comparison of 25(OH) Vitamin D Level on Day 7}

Serum 25(OH) vitamin D level was measured in $153(80.1 \%)$ of 191 patients 7 days after TICU admission. The mean $25(\mathrm{OH})$ vitamin D level in these patients was $9.4 \pm 7.5 \mathrm{ng} / \mathrm{ml}$. The GCS score, SOFA score, duration of MV, lengths of TICU and hospital stays, and rate of nosocomial infection differed significantly between patients with $25(\mathrm{OH})$ vitamin D level $<20 \mathrm{ng} / \mathrm{ml}$ and those with $25(\mathrm{OH})$ vitamin $\mathrm{D}$ level $\geq 20 \mathrm{ng} / \mathrm{ml}$ on day 7 . However, there were no statistically significant differences between these two groups in terms of age, sex, BMI, ISS, SAPS III, units of RBCs transfused, presence of shock, status of nutrition, and rate of mortality (Table 3 ).

Clinical Outcomes of TICU Patients That Showed Increased and Decreased 25(OH) Vitamin D Level from Day 1 to Day 7 of Hospitalization

Of the 153 patients, 57 (37.3\%) showed an increase and 96 patients $(62.7 \%)$ showed a decrease in $25(\mathrm{OH})$ vitamin $\mathrm{D}$ level from day 1 to day 7. The duration of MV, lengths of TICU and hospital stays, and nosocomial infection rate were significantly lower in patients in whom the level increased than in those in whom the level decreased, although there was no betweengroup difference for nutrition status and rate of mortality (Table 4).

Table 5. Logistic regression analysis for risk factors associated with nosocomial infection

\begin{tabular}{lccc}
\hline Variable & $\begin{array}{c}\text { Odds } \\
\text { ratio }\end{array}$ & $95 \% \mathrm{Cl}$ & P-value \\
\hline Injury severity score & 1.026 & $0.965-1.090$ & 0.416 \\
APACHE II score & 1.108 & $1.022-1.201$ & 0.013 \\
Presence of shock on admission & 0.269 & $0.073-0.998$ & 0.048 \\
RBC units transfused within 24 hours & 1.063 & $0.889-1.270$ & 0.502 \\
Nutrition $^{\text {a }}$ & 1.382 & $0.468-4.078$ & 0.558 \\
Operation within 7 days & 1.216 & $0.464-3.185$ & 0.691 \\
25(OH) vitamin D $\geq 20 \mathrm{ng} / \mathrm{ml}$ (day 1) & 4.106 & $0.566-29.812$ & 0.163 \\
25(OH) vitamin D $\geq 20 \mathrm{ng} / \mathrm{ml}$ (day 7) & 0.152 & $0.012-1.905$ & 0.144 \\
Increased 25(OH) vitamin D from & 0.719 & $0.276-1.873$ & 0.500 \\
$\quad$ day 1 and 7 & & & \\
Duration of MV (day) & 1.045 & $0.956-1.143$ & 0.330 \\
Length of TICU stay (day) & 1.088 & $0.995-1.189$ & 0.065 \\
Length of hospital stay (day) & 1.041 & $1.006-1.077$ & 0.022 \\
\hline
\end{tabular}

Cl: confidence interval; APACHE II: APACHE: Acute Physiology and Chronic Health Evaluation; RBC: red blood cell; 25(OH) vitamin D: 25-hydroxyvitamin D; MV: mechanical ventilation; TICU: trauma intensive care unit. ${ }^{a}$ Cases who were received enteral or parenteral nutrition for more than 3 days before the test of 7 days. 


\section{Logistic Regression Analysis for Risk Factors Associated with Nosocomial Infection}

Risk factors associated with nosocomial infection indicated that APACHE II score, presence of shock on admission, and length of hospital stay were independent factors, based on multivariate analysis (Table 5).

\section{DISCUSSION}

Vitamin D deficiency is a common problem in the general population [8-10]. The 2008 Korean National Health and Nutrition Examination Survey found that the prevalence of vitamin D insufficiency (25(OH) vitamin D level; $10-30 \mathrm{ng} / \mathrm{ml}$ ) was $82.6 \%$ and that of deficiency $(25(\mathrm{OH})$ vitamin $\mathrm{D}<10 \mathrm{ng} / \mathrm{ml})$ was $7.9 \%$ in the general Korean population [1]. Vitamin D deficiency is the most common nutritional deficiency in the United States [8]. The causes of vitamin D deficiency in the general population are multifactorial, including low vitamin D content in foods, blocking of vitamin D synthesis in the skin by the use of sunscreen, and reduced vitamin $\mathrm{D}$ synthesis in aging skin. In obesity, vitamin D is stored in fat cells instead of the liver. Chronic renal disease, liver failure, seasonal variations in exposure to sunlight in spring and winter, living in an urban area, and working indoors also are factors associated with vitamin D deficiency. The half-life of $25(\mathrm{OH})$ vitamin $\mathrm{D}$ is 15 days; hence, because trauma patients are often hospitalized after accidents in routine daily living, the initial vitamin D level in trauma patients is likely to be similar to that in the general population. Measurement of vitamin D level in trauma patients within 24 hours of TICU admission showed that almost all patients $(97.9 \%)$ had $25(\mathrm{OH})$ vitamin deficiency ( $<10 \mathrm{ng} / \mathrm{ml}$ ) or insufficiency (10-29 ng/ml). Similarly, a study on critically ill patients with traumatic injuries in the United States found that $96.2 \%$ had deficient or insufficient level of vitamin D [11]. However, these values were higher than in the general population mentioned above. Since vitamin D measurements for trauma patients were conducted after admission to the TICU and not immediately after arrival, fluid resuscitation in the emergency room, decreased serum calcium level due to RBC transfusion, and acute inflammatory conditions might have affected these differences.

In a study of traumatic patients in the United States, penetrating injuries, African-American race, and obesity were significant risk factors for vitamin D deficiency. In contrast, the severity of injury, extent of inflammation (elevated C-reactive protein level), and hospital admission in winter did not significantly influence the prevalence of vitamin D deficiency [11].
The results of our study were similar, but penetrating injuries did not affect our results. The initial level of bleeding was not large in the Korean cohort because the most common penetrating injuries in South Korea are stab injuries with a moderate degree of damage, in contrast to the majority of gun-shot penetrating injuries in the United States that are associated with a severe degree of damage. This is supported by the amount of RBCs transfused within 24 hours, and the corresponding decrease in total calcium level, which affected the vitamin D level in our study.

Although several studies have evaluated the relationship between vitamin $\mathrm{D}$ deficiency and clinical outcomes in critically ill patients, the associations between vitamin $\mathrm{D}$ level and clinical outcomes, such as the duration of MV, lengths of ICU and hospital stays, and mortality are unclear [5-19]. For example, in a previous study, the length of ICU stay, surgical ICU costs, and mortality were significantly associated with vitamin $\mathrm{D}$ deficiency [8]. Another previous study reported that serum $25(\mathrm{OH})$ vitamin D level within 24 hours of ICU admission was associated with prolonged hospitalization, readmission, and mortality, suggesting the need for randomized trials to determine whether vitamin D supplementation can improve these clinically relevant outcomes in surgical ICU patients [9]. A meta-analysis found that $25(\mathrm{OH})$ vitamin D level $<50 \mathrm{nmol} / \mathrm{L}$ $(<20 \mathrm{ng} / \mathrm{ml})$ was associated with high rates of infection, sepsis, 30-day mortality, and in-hospital mortality, suggesting that vitamin D deficiency increases the susceptibility of critically ill patients to severe infection and death [10]. In a previous study, patients with vitamin D deficiency or insufficiency had higher rates of complications and longer ICU and hospital stays than patients with normal vitamin D level [12]. Further, vitamin D deficiency had a significant impact on the length of stay, organ dysfunction, and the rate of infection [15]. Plasma 25(OH) vitamin D level measured on ICU admission was inversely associated with the duration of respiratory support [16]. Moreover, vitamin D status could be a modifiable risk factor for non-home discharge in surgical ICU patients [17], and vitamin D deficiency in patients with traumatic brain injury is associated with impaired cognitive function and severe depressive symptoms [18]. However, one study reported that although vitamin D insufficiency was associated with severe illness, vitamin D level was not significantly associated with the length of ICU stay or patient mortality [19]. Our study also found no significant differences between serum $25(\mathrm{OH})$ vitamin D level measured within 24 hours of TICU admission and clinical outcomes. Both the amount of RBCs transfused within 24 hours and the total calcium level 
were high in the group with low $25(\mathrm{OH})$ vitamin D level $(<20$ $\mathrm{ng} / \mathrm{ml}$ ) within 24 hours of TICU admission. A hypothesis for this is that serum dilution by massive resuscitation in the early stage and calcium reduction due to many RBC transfusions impact vitamin D level. In contrast, the duration of MV, lengths of TICU and hospital stays, and rate of nosocomial infection were significantly lower in patients with $25(\mathrm{OH})$ vitamin D $\geq 20 \mathrm{ng} / \mathrm{ml}$ than in those with $25(\mathrm{OH})$ vitamin $\mathrm{D}<20 \mathrm{ng} / \mathrm{ml}$ on day 7 of admission. Moreover, the duration of MV, lengths of TICU and hospital stays, and rate of nosocomial infection were significantly lower in patients in whom the $25(\mathrm{OH})$ vitamin D level increased from day 1 to day 7 than in patients in whom the level did not increase. On multivariate analysis, only APACHE II scores and the length of hospital stay were independent variables that affected the rate of nosocomial infection. Based on the above results, at first glance, the effects of vitamin D appear to be an important risk factor for clinical outcomes. However, it is unclear whether the clinical outcome was poor due to low vitamin D level or whether the presence of multiple complications and inflammation in severe trauma patients with poor clinical outcomes affected vitamin D level.

This study has several limitations. First, factors such as intake of vitamin D and drugs that affect vitamin metabolism before hospitalization, and the general environment of the patients, such as occupation, was not analyzed. Second, the heterogeneity of the trauma experienced by these patients and other variables could affect clinical outcomes. Third, the small sample size produced inevitable selection bias. Therefore, future studies with larger cohorts are required to corroborate these results. Although this study did not find a clear effect of vitamin D level on clinical outcomes in trauma patients, to our knowledge, this is the first study to examine vitamin D level in trauma patients in South Korea, and the study findings can be used as a basis for future investigations.

\section{CONFLICT OF INTEREST}

No potential conflict of interest relevant to this article was reported.

\section{ACKNOWLEDGMENTS}

This work was supported by a grant by the Biomedical Research Institute, Kyungpook National University Hospital (2018).

\section{ORCID}

Kyoung Hoon Lim https://orcid.org/0000-0002-6842-7129

Jihoon Jang

Jinyoung Park

https://orcid.org/0000-0003-4708-6203

\section{AUTHOR CONTRIBUTIONS}

Conceptualization: JP, KHL. Data curation, Formal analysis, \& Methodology: all authors. Funding acquisition: JJ. Project administration \& Visualization: all authors. Writing-original draft: JP. Writing-review \& editing: KHL.

\section{REFERENCES}

1. Choi HS, Oh HJ, Choi H, Choi WH, Kim JG, Kim KM, et al. Vitamin D insufficiency in Korea: a greater threat to younger generation: the Korea National Health and Nutrition Examination Survey (KNHANES) 2008. J Clin Endocrinol Metab 2011;96:643-51

2. Schwalfenberg GK. A review of the critical role of vitamin D in the functioning of the immune system and the clinical implications of vitamin D deficiency. Mol Nutr Food Res 2011;55: 96-108.

3. Jeng L, Yamshchikov AV, Judd SE, Blumberg HM, Martin GS, Ziegler TR, et al. Alterations in vitamin D status and anti-microbial peptide levels in patients in the intensive care unit with sepsis. J Transl Med 2009;7:28.

4. Holick MF, Binkley NC, Bischoff-Ferrari HA, Gordon CM, Hanley DA, Heaney RP, et al. Evaluation, treatment, and prevention of vitamin D deficiency: an Endocrine Society clinical practice guideline. J Clin Endocrinol Metab 2011;96:1911-30.

5. Lee P, Nair P, Eisman JA, Center JR. Vitamin D deficiency in the intensive care unit: an invisible accomplice to morbidity and mortality? Intensive Care Med 2009;35:2028-32.

6. Lee P, Eisman JA, Center JR. Vitamin D deficiency in critically ill patients. N Engl J Med 2009;360:1912-4.

7. Higgins DM, Wischmeyer PE, Queensland KM, Sillau SH, Sufit AJ, Heyland DK. Relationship of vitamin D deficiency to clinical outcomes in critically ill patients. JPEN J Parenter Enteral Nutr 2012;36:713-20.

8. Matthews LR, Ahmed Y, Wilson KL, Griggs DD, Danner OK. Worsening severity of vitamin $\mathrm{D}$ deficiency is associated with increased length of stay, surgical intensive care unit cost, and mortality rate in surgical intensive care unit patients. Am J Surg 2012;204:37-43.

9. Quraishi SA, Bittner EA, Blum L, McCarthy CM, Bhan I, Ca- 
margo CA Jr. Prospective study of vitamin D status at initiation of care in critically ill surgical patients and risk of 90-day mortality. Crit Care Med 2014;42:1365-71.

10. de Haan K, Groeneveld AB, de Geus HR, Egal M, Struijs A. Vitamin $\mathrm{D}$ deficiency as a risk factor for infection, sepsis and mortality in the critically ill: systematic review and meta-analysis. Crit Care 2014;18:660.

11. Dickerson RN, Van Cleve JR, Swanson JM, Maish GO 3rd, Minard G, Croce MA, et al. Vitamin D deficiency in critically ill patients with traumatic injuries. Burns Trauma 2016;4:28.

12. Blay B, Thomas S, Coffey R, Jones L, Murphy CV. Low vitamin $D$ level on admission for burn injury is associated with increased length of stay. J Burn Care Res 2017;38:e8-13.

13. Gueye Y, Marqueste T, Maurel F, Khrestchatisky M, Decherchi P, Feron F. Cholecalciferol (vitamin $\mathrm{D}_{3}$ ) improves functional recovery when delivered during the acute phase after a spinal cord trauma. J Steroid Biochem Mol Biol 2015;154:23-31.

14. Toman E, Bishop JR, Davies DJ, Su Z, Criseno S, Mason A, et al. Vitamin $\mathrm{D}$ deficiency in traumatic brain injury and its relationship with severity of injury and quality of life: a prospec- tive, observational study. J Neurotrauma 2017;34:1448-56.

15. Flynn L, Zimmerman LH, McNorton K, Dolman M, Tyburski J, Baylor A, et al. Effects of vitamin D deficiency in critically ill surgical patients. Am J Surg 2012;203:379-82.

16. Quraishi SA, McCarthy C, Blum L, Cobb JP, Camargo CA Jr. Plasma 25-Hydroxyvitamin D levels at initiation of care and duration of mechanical ventilation in critically ill surgical patients. JPEN J Parenter Enteral Nutr 2016;40:273-8.

17. Brook K, Camargo CA, Christopher KB, Quraishi SA. Admission vitamin $\mathrm{D}$ status is associated with discharge destination in critically ill surgical patients. Ann Intensive Care 2015;5:23.

18. Jamall OA, Feeney C, Zaw-Linn J, Malik A, Niemi ME, Tenorio-Jimenez $\mathrm{C}$, et al. Prevalence and correlates of vitamin $\mathrm{D}$ deficiency in adults after traumatic brain injury. Clin Endocrinol (Oxf) 2016;85:636-44.

19. Anwar E, Hamdy G, Taher E, Fawzy E, Abdulattif S, Attia MH. Burden and outcome of vitamin D deficiency among critically ill patients: a prospective study. Nutr Clin Pract 2017;32:37884. 